\title{
Test Results of Fuel Additive in the Boiler with Grate Firing of Coal
}

\author{
Vasily I. Murko*a, \\ Victor I. Karpenok ${ }^{a}$, Vasily I. Fedyaeva, \\ Dmitry A. Chernykh ${ }^{a}$, Evgeny N. Zelikov'b, \\ Andrey V. Solovyov and Alexander M. Zhavoronkov ${ }^{\mathrm{d}}$ \\ aSPE "Sibecotechnika", CJSC \\ 2 Kommunarov, Novokuznetsk, 654079, Russia \\ ${ }^{b}$ GISEnergo, LLC \\ 8 a Strastnoy blvd., Moscow, 107031, Russia \\ ${ }^{c}$ National Association of Producers and Consumers \\ of Ash and Slag materials \\ 2 Volokolamskoe Shosse, Moscow, 125080, Russia \\ "Municipal Enterprise "The Siberian Sales Company" \\ 12/1 Ordzhonikidze Str., Novokuznetsk, 654000, Russia
}

Received 18.03.2017, received in revised form 09.07.2017, accepted 20.11.2017

Now the domestic heat-and-power engineering has no experience of use of fuel additives to increase efficiency of fuel usage in coal boilers. However abroad this direction of increase in efficiency of combustion of solid fuels has been widely adopted, that, first of all, is caused by search of technologies for "ecologization" of use of "dirty" coal. The article contains the results of industrial tests of complex fuel additive of catalyzing and modifying action in the coal boiler KV-r-11.63-115 in one of the boiler houses in Novokuznetsk, Kemerovo region. The test results showed increase in gross efficiency of the boiler unit for 5,1\% (abs.) along with the corresponding decrease in consumption of coal fuel to produce one unit of heat energy. Application of the additive also led to cleaning of furnace tube from a layer of deposits and changing of structure of slag formed at combustion of coal which became more homogeneous and without agglomeration centers.

Keywords: fuel additive, coal fuel, boiler efficiency, heating surface.

Citation: Murko V.I., Karpenok V.I., Fedyaev V.I., Chernykh D.A., Zelikov E.N., Solovyov A.V., Zhavoronkov A.M. Test results of fuel additive in the boiler with grate firing of coal, J. Sib. Fed. Univ. Eng. technol., 2017, 10(8), 993-999. DOI: 10.17516/1999494X-2017-10-8-993-999.

(C) Siberian Federal University. All rights reserved

* Corresponding author E-mail address: sib_eco@kuz.ru 


\title{
Результаты испытаний топливной присадки \\ на котле со слоевым сжиганием угля
}

\author{
В.И. Мурко ${ }^{\text {, В.И. Карпенок }}{ }^{\mathrm{a}}$, \\ В.И. Федяев ${ }^{\mathrm{a}}$, Д.А. Черных ${ }^{\mathrm{a}}$, \\ Е.Н. Зеликов ${ }^{\sigma}$, А.В. Соловьев ${ }^{\text {, }}$ А.Н. Жаворонков ${ }^{г}$ \\ аЗАО НПП «Сибэкотехника» \\ Россия, 654079, Новокузнецк, пр-д Коммунаров, 2 \\ ${ }^{\sigma} О О О$ «ГИСЭнерго» \\ Россия, 107031, Москва, Страстной б-р, 8 а \\ ${ }^{8}$ Национальная ассочиаџия производителей \\ и потребителей золошлаковых материалов (НАППЗШМ) \\ Россия, 125080, Москва, Волоколамское шоссе, 2 \\ ${ }^{2}$ МП «Сибирская сбытовая компания» \\ Россия, 654000, Новокузнеик, ул. Орджоникидзе, 12/1
}

В настоящее время в отечественной теплоэнергетике отсутствует опыт применения топливных присадок для повышения эффективности топливоиспользования в угольных котлах. Однако за рубежом данное направление увеличения эффективности сжигания твердых топлив получило широкое распространение, что, в первую очередь, обусловлено поиском технологий «экологизации» использования «грязного» угля. В статье приводятся результаты промыиленных испытаний комплексной топливной присадки катализирующчего и модифицирующего действия на угольном котле КВ-р-11.63-115 в одной из котельных г. Новокузнецка Кемеровской области. По результатам испытаний зафиксировано повышение к.п.д. брутто котельного агрегата на 5,1\% (абс.) при соответствующем снижении расхода условного топлива на выработку единицы тепловой энергии. Применение присадки привело также к очистке экранных труб от слоя натрубных отложений и изменению структуры образующегося при сгорании угля шлака, который стал более однородным и без очагов агломерации.

Ключевые слова: топливная присадка, угольное топливо, к.п.д. котла, поверхности нагрева.

\section{Введение}

Специалисты многих стран предсказывают в перспективе увеличение потребления угля в общем энергетическом балансе. Прогнозируется также постепенный переход от чисто энергетического к энерготехнологическому и энергохимическому применению углей. Значительная доля перерабатываемых в будущем углей может быть основана на использовании российских углей в силу их высокого качества и значительности запасов.

В настоящее время в Российской Федерации возрос интерес к высокоэффективному использованию угольных топлив в малой и средней энергетике.

Вместе с тем, использование угля или продуктов его переработки требует разработки экологически чистых технологий, так как сжигание угля сопровождается выделением вредных веществ в атмосферу [1].

Если в отечественной теплоэнергетике имеется опыт использования топливных присадок для улучшения сжигания мазутного топлива, то на угольных котлах данная технология практически не применяется [2]. 
Вместе с тем, зарубежный опыт (США, страны ЕС, Индия, Китай) [3-10] указывает на то, что применение топливных присадок на угольных котлах различной мощности не только обеспечивает интенсификацию и активизацию процесса горения угольного топлива, но и способствует улучшению состояния поверхностей нагрева и снижению уровня вредных выбросов в атмосферу. Одной из главных причин низкого интереса отечественной угольной энергетики к данной технологии улучшения качества сжигания твердого топлива является отсутствие какого-либо опыта практического применения топливных присадок.

В сентябре 2015 г. по инициативе Национальной ассоциации производителей и потребителей золошлаковых материалов (НАППЗШМ) были организованы и совместно с НПП «Сибэкотехника» (г. Новокузнецк) проведены на угольной котельной г. Новокузнецка промышленные испытания одной из перспективных топливных присадок зарубежного производства (3Н Korea Co.Ltd).

\section{Материалы, оборудование и методы испытаний}

Промышленные испытания топливной присадки проводили на угольном водогрейном котле КВ-р-11, 63-115. Техническая характеристика котла представлена в табл. 1.

Сжигание угля в котле слоевое с использованием топки обратного хода типа ТЧМЗ. Предварительно дробленый уголь кл. 0-20 мм из бункера поступает на питатель пневмомеханического типа и забрасывается на решетку. Горение на решетке происходит в тонком слое, толщина которого устанавливается в зависимости от марки угля и требуемой теплопроизводительности котла. Одновременно при работе котла выбирается режим подачи дутьевого воздуха под решетку. Шлак с решетки удаляется непрерывно при перемещении колосникового полотна в направлении к фронту котла.

В качестве топливной присадки использовалась комплексная жидкая добавка Aid-Clean Force (3H Korea Co.Ltd) катализирующего и модифицирующего действия, состоящая из на-

Таблица. 1. Техническая характеристика котла

Table. 1. Technical characteristics of the boiler

\begin{tabular}{|c|c|c|}
\hline Показатели & Единица измерения & Величина \\
\hline Номинальная теплопроизводительность & МВт (Гкал/ч) & $11.63(10)$ \\
\hline Номинальный расход воды через котел, не менее & $\mathrm{T} / \mathrm{Y}$ & 123,5 \\
\hline Диапазон регулирования & $\%$ & $25 \div 100$ \\
\hline Рабочее давление & МПа (кге/см²) & $2.5(25.5)$ \\
\hline Номинальная температура воды на выходе из котла & ${ }^{\circ} \mathrm{C}$ & 115 \\
\hline Номинальная температура воды на входе в котел & ${ }^{\circ} \mathrm{C}$ & 70 \\
\hline Гидравлическое сопротивление котла, не более & 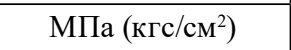 & $0.25(2.5)$ \\
\hline $\begin{array}{l}\text { Габариты компоновки котла: } \\
\text { - глубина } \\
\text { - ширина } \\
\text { - высота }\end{array}$ & м & $\begin{array}{l}7.430 \\
5.230 \\
10.810\end{array}$ \\
\hline
\end{tabular}


Таблица. 2. Физические свойства присадки

Table. 2. Physical properties of the additive

\begin{tabular}{|c|c|c|}
\hline Наименование показателя & Единица измерения & Значение \\
\hline Размер частицы дисперсной фазы & HM & $10-50$ \\
\hline Удельная поверхность & $\mathrm{M}^{2} / \mathrm{Mл}$ & 200 \\
\hline Удельный вес & $\kappa \Gamma / \mathrm{M}^{3}$ & 1.14 \\
\hline $\mathrm{pH}$ & $\sigma / p$ & $6-8$ \\
\hline Морозостойкость & ${ }^{\circ} \mathrm{C}$ & -20 \\
\hline
\end{tabular}

нооксида алюминия $\left(\mathrm{Al}_{2} \mathrm{O}_{3}\right)$, наногидроталькита $\left(\mathrm{Mg}_{6} \mathrm{Al}_{2}\left(\mathrm{Co}_{3}\right)(\mathrm{OH})_{16} .4 \mathrm{HO}\right)$, пероксида водорода $\left(\mathrm{H}_{2} \mathrm{O}_{2}\right)$ и др. Физические свойства присадки представлены в табл. 2.

Приготовление топливной присадки перед использованием осуществлялось следующим образом. Предварительно концентрированный раствор присадки разбавлялся водой до соотношения 1:10 (раствор : вода) и тщательно перемешивался до получения однородной массы. Полученный раствор фильтровался и дозирующим насосом подавался через форсунку на дробленый уголь, транспортируемый ленточным конвейером в угольный бункер перед котлом в процессе его загрузки.

Расход топливной добавки составлял 10 $\div 11$ кг готового раствора на 1 т угля.

Орошение загружаемого в бункер угля производилось периодически в соответствии с установленным в котельной графиком заполнения бункеров.

Эффективность действия топливной присадки оценивалась путем проведения балансовых испытаний котла до введения присадки и после при различной производительности с последующих расчетом основных технико-экономических показателей методом обратного баланса.

В процессе проведения испытаний отбирали и анализировали пробы угля, шлака, золы уноса и производили измерения состава дымовых газов с применением газоанализатора Testo3000. Кроме того, до и после испытаний фиксировалось состояние поверхностей нагрева котла в районе топочного пространства, а именно оценивались степень их загрязнения и структура натрубных отложений.

\section{Анализ результатов испытаний}

Результаты работы котла с применением присадки и без присадки на разных мощностях представлены в табл. 3 и на графике (рис. 1).

Как видно по результатам испытаний, применение присадки привело к увеличению к.п.д. котла до 75,2 \%, что на 10,8 \% выше значения по режимной карте. При этом значение к.п.д. непрерывно увеличивалось в процессе проведения испытаний (как с присадкой, так и без нее), что можно объяснить улучшением состояния экранных поверхностей нагрева за счет действия топливной присадки (рис. 2 и 3). Отмечено снижение горючих веществ как в шлаке, так и в золе уноса под действием присадки, что привело к уменьшению потерь тепла с механическим недожогом.

Как видим на рис. 4 и 5, ввод топливной присадки повлиял на структуру образующегося при сгорании угля шлака, которая стала более рыхлой и однородной.

$$
-996-
$$


Таблица. 3. Показатели эффективности сжигания угля без присадки и с присадкой при работе котла на разных мощностях

Table. 3. Indicators of the efficiency of coal combustion without additive and with an additive when the boiler is operating at different capacities

\begin{tabular}{|c|c|c|c|c|c|}
\hline \multirow{3}{*}{$\begin{array}{c}\text { Теплопроизво- } \\
\text { дительность, Гкал/ч }\end{array}$} & \multicolumn{4}{|c|}{ Параметры работы котла (с присадкой/без присадки) } & \multirow{3}{*}{$\begin{array}{c}\text { к.п.д. брутто } \\
\text { по режимной } \\
\text { карте, \% }\end{array}$} \\
\hline & \multirow{2}{*}{$\begin{array}{l}\text { Потери с мех. } \\
\text { недожогом, q4, \% }\end{array}$} & \multicolumn{2}{|c|}{ Содержание горючих, \% } & \multirow{2}{*}{$\begin{array}{c}\text { к.П.д. } \\
\text { брутто, \% }\end{array}$} & \\
\hline & & В шлаке & В золе уноса & & \\
\hline $2-3$ & $10.7 / 20.8$ & $31.4 / 46.2$ & $49.9 / 60.1$ & $63.0 / 60.0$ & 62.0 \\
\hline $3-4$ & $9.6 / 18.6$ & $30.2 / 44.6$ & $45.2 / 60.0$ & $61.8 / 60.0$ & 64.7 \\
\hline $4-5$ & $5.9 / 8.6$ & $18.2 / 24.4$ & $43.5 / 53.4$ & $68.8 / 68.1$ & 65.2 \\
\hline $5-6$ & $7.0 / 9.0$ & $18.8 / 25.3$ & $46.1 / 53.5$ & 71.4 / 69.1 & 65.0 \\
\hline $6-8$ & $6.8 / 10.1$ & $17.8 / 29.0$ & $47.1 / 51.2$ & $75.2 / 70.1$ & 64.4 \\
\hline
\end{tabular}

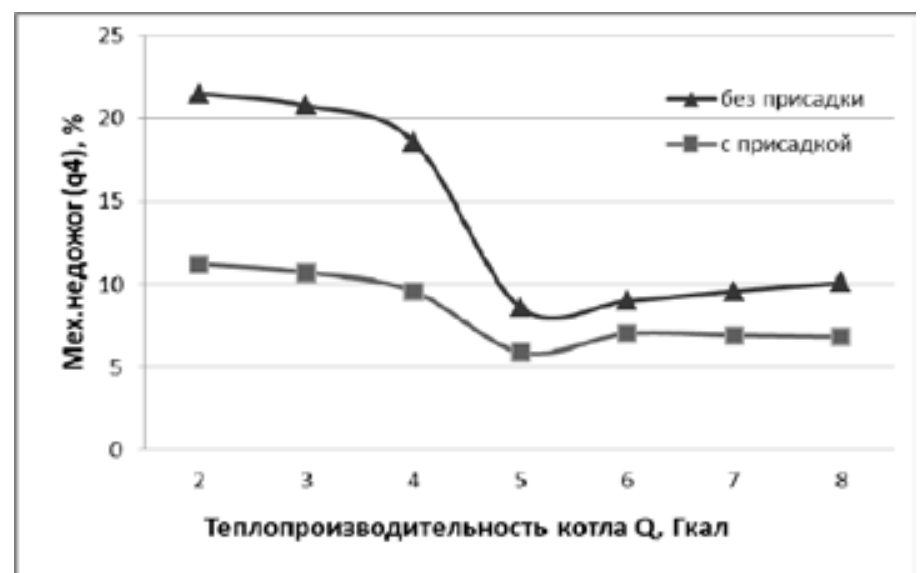

Рис. 1. График эффективности сжигания угля при работе котла на разных мощностях

Fig. 1. Graph of the efficiency of coal combustion during boiler operation at different capacities

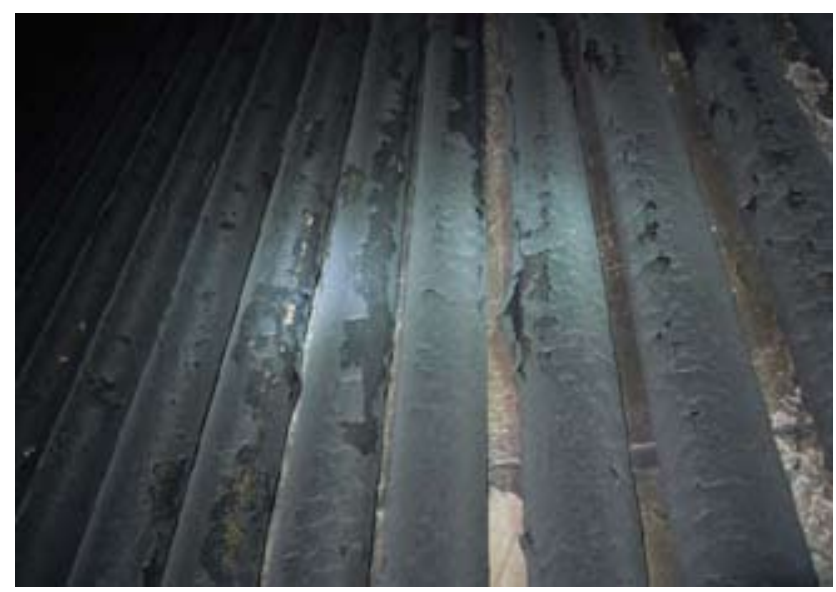

Рис. 2. Вид труб левого экрана до применения присадки

Fig. 2. Type of pipes of the left screen before application of the additive 


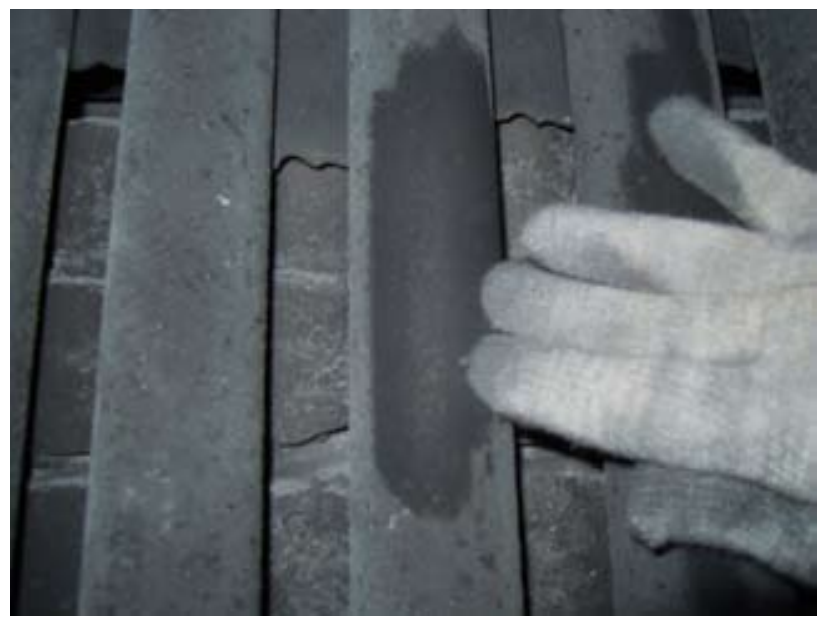

Рис. 3. Вид труб левого экрана после испытаний

Fig. 3. Type of tubes of the left screen after the tests

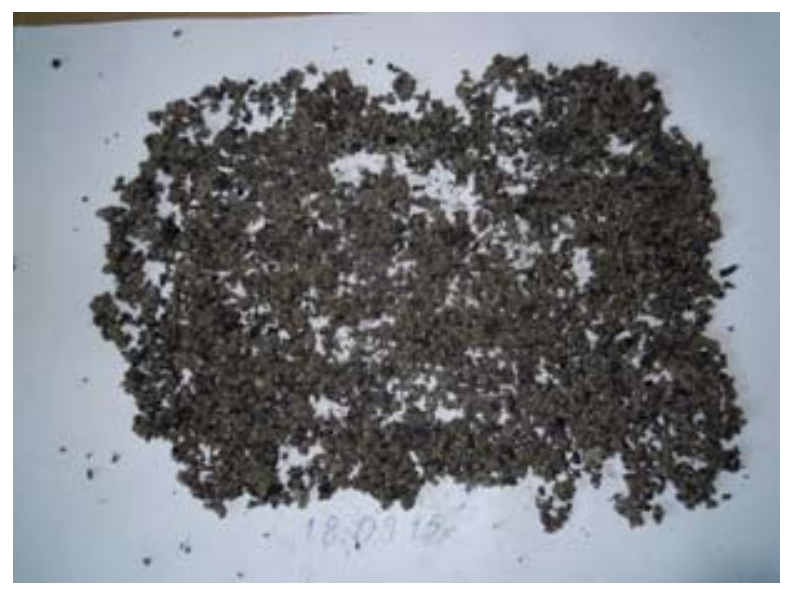

Рис. 4. Шлак при использовании присадки

Fig. 4. Slag when using an additive

\section{Выводы}

Результаты проведенных испытаний позволяют сделать следующие выводы:

1. При работе котла с добавлением присадки было достигнуто значение КПД 75,2 \%, что на 10,8 \% выше, чем в режимной карте работы котла (64,4\%). При этом снижение расхода условного топлива на производство 1 Гкал тепловой энергии при использовании присадки составило 30 кг.

Применение присадки обеспечило снижение содержания горючих в шлаке и уносе, что, соответственно, уменьшило потери тепла с мехнедожогом на 2950 \% относительных.

2. Отмечено, что применение присадки привело к изменению структуры шлака, а именно снижению количества крупных агломератов и, соответственно, к увеличению доли мелких классов. 
3. Установлено, что применение присадки привело к очистке экранных труб котла от имевшихся отложений и к дальнейшему поддержанию поверхностей нагрева в эксплуатационно-чистом состоянии.

4. Отмечена повышенная эффективность работы котла после окончания испытаний присадки, что может быть следствием сохранения эффекта чистоты поверхностей нагрева.

Исследование выполнено при финансовой поддержке Российского фонда фундаментальных исследований, Правительства Красноярского края, Красноярского краевого фонда поддержки научной и научно-технической деятельности» в рамках научного проекта № 17-48-240386 p_a.

\section{Список литературы}

[1] Мурко В.И., Журавлева Н.В., Федяев В.И. и др. Экологические аспекты вихревой технологии сжигания суспензионного угольного топлива. Экология и промышленность России. 2009. № 1. 6-9 [Murko V.I., Zhuravleva N.V., Fedyaev V.I. etc. Ecological aspects of vortex technology for combustion of suspended coal fuel. Ecology and Industry of Russia. 2009. No. 1. 6-9 (in Russia)].

[2] Белосельский Б.С. Применение присадок многофункционального действия к топочным мазутам, сжигаемым на электростанциях, Новое в российской электроэнергетике. 2005. № 10 [Beloselsky B.S. Application of multifunctional additives to furnace fuel oils burned at power plants, New in the Russian Power Industry. 2005. No. 10 (in Russia)].

[3] Coal combustion catalyst. Coal-CC919L (Liquid), Report TDS paper. 2007. 7 p.

[4] Smyrniotis Chris R. Slag inhibition success utilizing targeted in-furnace injection at a PRB coal burning utility boiler, World of Coal Ash (WOCA) Conference "Science, Applications and Sustainability, Lexington, Ky, Apr. 11-15, 2005: Proceedings. Lexington (Ky): Univ. Kentucky Cent. Appl. Energy Res.; Lexington (Ky): Amer. Coal Ash Assoc. 2005, 35-57.

[5] Cheng Jun, Zhou Jun-hu, Liu Jian-zhong, Fan Hong-yu, Cao Xin-yu, Li Zhen-yu, Cen Ke-fa, Zhongguo dianji gongcheng xuebao, Institute for Thermal Power Engineering, Zhejiang University, Hangzhou 310027, Proc. Chin. Soc. Elec. Eng. 2002. 22, No 9, 128-131.

[6] Wu Zenghua, Yu Zhiwu, Zhu Wentao, Zhou Rui. Energy saving and pollution reducing effects of coal combustion catalysts, Tsinghua Sci. and Technol. 2001. 6, No 2, 156-159.

[7] Ma Zhen-xing, Guo Ju-xiou, Li Jing Reneng dongli gongchengv, J. Eng. Therm. Energy and Power. 2001. 16, No 6, 579-581.

[8] Zhao Conghong, Bai Yu, Huyan Weidong, Neimenggu dianli jishu. Inn. Mongolia Elec. Power. 2000. 18, No 3, 27.

[9] Henderson P., Andersson C., Kassman H. The use of fuel additives in wood and waste woodfired boilers to reduce corrosion and fouling problems, VGB Power Tech. 2004. No 6, 58-62.

[10] Johnson Stephen Allen, Wurster John, Comer John Philip. Low sulfur coal additive for improved furnace operation, ADA Environmental Solutions, LLC, No 09/893079 - 04.05.2004. 